\title{
Preparation and Characterization of an Electrospun PLA-Cyclodextrins Composite for Simultaneous High-Efficiency PM and VOC Removal
}

\author{
Silvia Palmieri ${ }^{1, *}$, Mattia Pierpaoli ${ }^{2, *} \mathbb{( D}$, Luca Riderelli ${ }^{3}$, Sheng $\mathrm{Qi}^{4}{ }^{4}$ \\ and Maria Letizia Ruello ${ }^{1, *(\mathbb{D})}$ \\ 1 Department of Materials, Environmental Sciences and Urban Planning-(SIMAU), \\ Università Politecnica delle Marche, 60121 Ancona, Italy \\ 2 Department of Metrology and Optoelectronics, Faculty of Electronics, Telecommunication and Informatics, \\ Gdańsk University of Technology, 80-233 Gdańsk, Poland \\ 3 Via Bartolini 13/A, 60027 Osimo, Ancona, Italy; lucariderelli@gmail.com \\ 4 School of Pharmacy, University of East Anglia, Norwich Research Park, Norwich NR4 7TJ, UK; \\ sheng.qi@uea.ac.uk \\ * Correspondence: s.palmieri@pm.univpm.it (S.P.); mattia.pierpaoli@pg.edu.pl (M.P.); \\ m.l.ruello@univpm.it (M.L.R.)
}

Received: 4 June 2020; Accepted: 17 June 2020; Published: 23 June 2020

\begin{abstract}
Electrospinning is known to be a facile and effective technique to fabricate fibers of a controlled diameter-distribution. Among a multitude of polymers available for the purpose, the attention should be addressed to the environmentally compatible ones, with a special focus on sustainability. Polylactic acid (PLA) is a widespread, non-toxic polymer, originating from renewable sources and it can degrade into innocuous products. While the production of fibrous membranes is attractive for airborne particles filtration applications, their impact on the removal of gaseous compounds is generally neglected. In this study, electrospun PLA-based nanofibers were functionalized with cyclodextrins, because of their characteristic hydrophobic central cavity and a hydrophilic outer surface, in order to provide adsorptive properties to the composite. The aim of this work is to investigate a hybrid composite, from renewable sources, for the combined filtration of particulate matter (PM) and adsorption of volatile organic compounds (VOCs). Results show how their inclusion into the polymer strongly affects the fiber morphology, while their attachment onto the fiber surface only positively affects the filtration efficiency.
\end{abstract}

Keywords: polylactic acid; electrospinning; nanofibers; air filtration

\section{Introduction}

Air filtration is the most effective and widespread method to remove particulate matters (PM) from the air stream. Air filter material and morphology plays a major role in the process efficiency and sustainability. Electrospinning is a versatile method commonly used to manufacture polymer nanofiber [1].

The concept of green electrospinning has been introduced with the aim of reducing the toxicity and environmental problem related to the use of potentially hazardous-organic solvents for the electrospinning of natural or synthetic polymers [2]. While this aspect is of primary importance in regenerative medicine, in which the absence of impurity is compulsory, when the electrospun fiber mat is used in much larger extends for air filtration applications, the focus should be addressed to the polymer type as well, favoring polymer from renewable sources, easily disposable, and having a low environmental impact. Since indoor air quality has become not only an issue but also a need, 
due to the risks people are exposed to and in connection with the amount of time spent in confined environment, both at work and home [3]. In addition to common pollutants of outdoor air, it must be considered that there are other unusual sources like furniture, copiers, and air fresheners. Moreover, people themselves are a source of potentially harmful agents i.e., spread as indoor bioaerosol.

Electrospinning of functional polymeric nanofibers has attracted considerable attention in the past decade due to the simplicity of the process and the enhanced properties associated with the size of the fibers [4-6]. One potential application for electrospun nanofibers is in the field of filtration where the nanowebs can provide separation of tiny particles due to the different interception mechanism.

Polylactic acid (PLA) is a thermoplastic aliphatic polyester derived from renewable resources, so it has been chosen for its environmentally friendly properties, such as its biodegradability.

The fabrication of PLA electrospun nanofibers has been widely investigated by many authors because of their great availability, their production from renewable sources, their non-toxicity, and their known biodegradability [7-9].

Casasola and co-workers [10] investigated the effect of different solvents on the fiber morphology. In particular, they found that the acetone-based binary solvent system was the most effective to produce electrospinnable nanofibers.

In the study of Wang et al. [11], porous bead-on-string polylactic acid nanofibrous membranes (NMs) were fabricated to investigate their filtration performance by measuring the penetration of sodium chloride $(\mathrm{NaCI})$ aerosol particles. Without further modification, a high filtration efficiency was obtained, by controlling the solvent solution.

Cyclodextrins (CyDs) are conical, truncated macrocycles, consisting of six, seven, and eight $\alpha$-d-glucose units, and named $\alpha-, \beta-$, and $\gamma-$, respectively (Figure 1) [12].<smiles>CC(OC(=O)C(C)OC(C)C(=O)O)C(=O)O</smiles>

(a)

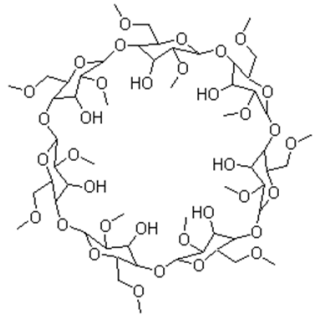

(b)

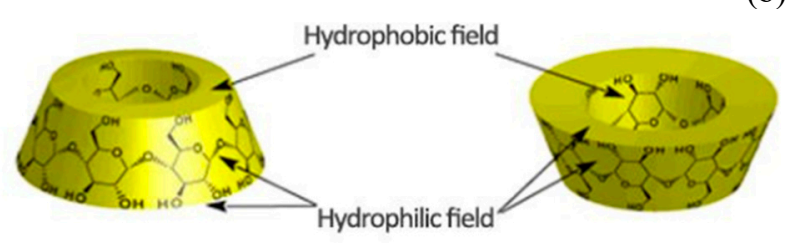

(c)

Figure 1. (a) poly(lactic acid) (PLA) chemical structure; (b) cyclodextrin (CyD) chemical structure; and (c) representation of CyD structure.

They are environmentally friendly and deserve attention for their valuable properties thanks to their chemical structure. In fact, they are commonly applied in different fields: From pharmaceutical carriers [12-14], to use as nano-sponges in water treatments [13,15]. Cyclodextrins can form complexes of inclusion with numerous poorly soluble molecules, this is the reason why they are commonly used in pharmaceutical chemistry as carriers. Hydrophobic molecules are maintained in the cavity of the cyclodextrin with the outer surface of the complex maintaining its hydrophilic characteristics [12,16]. Wen and colleagues [17] incorporated cinnamon essential oil/beta-cyclodextrin into PLA nanofilm to give better antimicrobial activity compared to conventional nanofilm, prolong the shelf life of food, and act as an active food packaging. Similarly, in the works of Aytac et al. [18], beta-cyclodextrin 
was used for the stabilization of active compounds in the production of functional electrospun PLA nanofibers incorporating naturally occurring antioxidant compound.

Taking advantages of their molecular structure to block lipophilic molecules [19], such as volatile organic compounds (VOCs), another use for cyclodextrins has been proposed $[20,21]$ for air pollution control applications. While cyclodextrins have already been used for the removal of organic pollutants in wastewater $[15,21,22]$, they have not been used in much lesser extends for air treatments and removal of PMs and VOCs.

In this study, for the first time, an electrospun PLA/cyclodextrin composite has been produced and characterized for the joint filtration of particulate matter and enhanced adsorption of VOCs. The electrospun nanocomposite exhibits not only excellent PM filtration efficiency, but the presence of $\mathrm{CyD}$ provides, to the composite material, a two-fold improved adsorption ability measured in terms of toluene removal.

\section{Materials and Methods}

\subsection{Material}

Dichloromethane (DCM) and N,N-dimethylformamide (DMF) of analytical grade were purchased from Sigma-Aldrich. PLA was used to prepare a polymeric solution of $8 \% \mathrm{w} / \mathrm{V}$ solubilized in DCM/DMF (80:20). The electrospinning setup consisted of a house-made syringe pump, in which the needle was connected to the high potential $(16 \mathrm{kV})$. The flow rate was $0.5 \mathrm{~mL} / \mathrm{h}$ and the needle/collector distance was equal to $10 \mathrm{~cm}$. Nanofibers were electrospun over a PLA-based 3D printed support and placed on a grounded aluminum foil (see supplementary materials).

All the prepared composites were electrospun over 3D-printed support (1mm thick) with large voids (60\% fill). Pictures of the substrate and 3D printing parameters are reported in the supporting materials. Both support and nanofibers produced with electrospinning technique were made by the same polymer to improve the affinity, permitting a better adhesion between them [23]. In this study B-methyl-cyclodextrins (Carbosynth) has also been used, either in association with fibers such as in powder or solubilized in methanol (Sigma-Aldrich) and electrospun. Cyclodextrins were both incorporated in the PLA solution, both dispersed on the PLA surface. Three different configurations were studied: (a) PLA was solubilized in the solvent and then electrospun (PLA); (b) a three levels configuration where a layer of cyclodextrins in powder was placed in the middle of a bi-layer of electrospun PLA (PLA/CyD); and (c) cyclodextrins were solubilized in a few droplets of methanol and added in the same solution of PLA then electrospun (PLA + CyD).

\subsection{Characterization}

All the specimens have been analyzed with a ZEISS scanning electron microscope for the characterization of the morphological aspect and to evaluate the interaction between PLA fibers and $\mathrm{CyD}$.

The samples were analyzed by using a Perkin-Elmer Spectrum GX1 spectrometer (PerkinElmer, Inc, Waltham, MA, USA) equipped with U-ATR accessory for the analysis of solid samples in reflectance mode. On each sample, five spectra were acquired in the range between $4000-500 \mathrm{~cm}^{-1}$, with a spectral resolution of $4 \mathrm{~cm}^{-1}$ and recording 64 scans. A background adsorption spectrum was recorded before each acquisition. Raw FTIR spectra were converted into absorbance, interpolated in the $1800-500 \mathrm{~cm}^{-1}$ spectral range, and vector normalized in the same interval. An automatic baseline correction algorithm was used in all spectra to avoid errors due to baseline shifts. Atmospheric compensation was also performed. The average absorbance spectra of all samples were also calculated, and they were fitted in the 1800-800 $\mathrm{cm}^{-1}$ upon two-points baseline correction and vector normalization (Grams AI 9.1 software, Galactic Industries, Inc., Salem, NH). A Gaussian algorithm was adopted. For each underlying band, the positions in terms of wavenumbers, height, and integrated area were calculated. Spectrum 5.3.1 (Perkin-Elmer) was used as the operating software. 


\subsection{PM Generation and Efficiency Tests}

In the filtration efficiency tests, PM particles were generated by burning incense in an 821 box. The smoke PM particles had a wide size distribution from $<300 \mathrm{~nm}$ to $4 \mu \mathrm{m}$, with the majority of particles being $<1 \mu \mathrm{m}$. The so-generated particle stream was controlled by dilution with air. PM particle number concentration was measured with a GRIMM 1.108 particle counter and the removal efficiency was calculated by comparing the number concentration before and after filtration, while the pressure drop in the filter medium was measured by a differential pressure meter (Honeywell 160 PC). The wind velocity, was measured in absence of the filter with a hot-wire anemometer, was equal to $1.4 \mathrm{~m} \mathrm{~s}^{-1}$.

VOC removal tests were performed in the same box environments, with the injection of $100 \mu \mathrm{L}$ Toluene, and the test started when its full vaporization occurred. VOC concentration was measured with a ppbRAE 3000 with 1-min sample time, and the VOC removal efficiency was calculated, likewise for $\mathrm{PM}$, by comparing the number concentration before and after filtration. All the tests were performed at the temperature of $27 \pm 2{ }^{\circ} \mathrm{C}$ and relative humidity equal to $50 \pm 10 \%$.

\section{Results}

\subsection{Electrospun Nanofiber Morphology}

Figure 2 reports SEM pictures of the three reference filter composites, with only PLA (Figure 2a), with the addition of $\mathrm{CyD}$ in bulk solution (Figure 2b), and over the PLA fiber (Figure 2c). The median diameters of the PLA-based fiber composites electrospun from the solutions were determined to be 350, 990, and $530 \mathrm{~nm}$, respectively (Figure 3.)
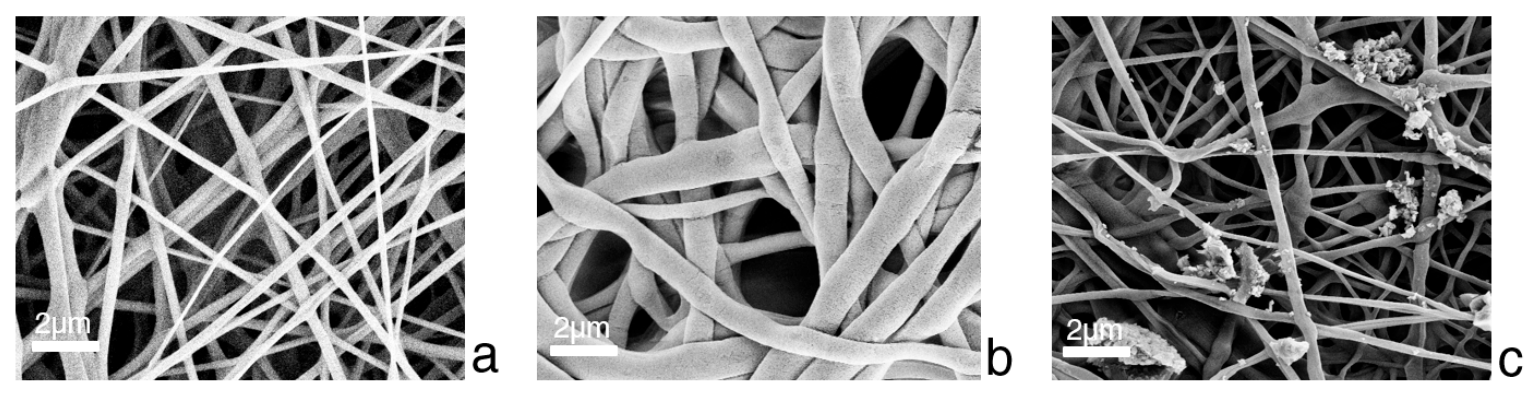

Figure 2. SEM pictures of (a) PLA, (b) PLA/CyD, and (c) PLA+CyD electrospun nanofibers.

PLA

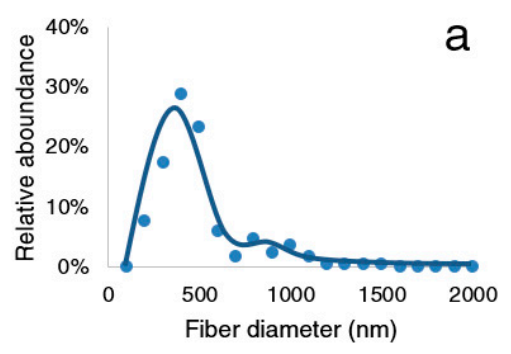

Figure 3. Fiber diameter electrospun nanofibers.
PLA/CyD

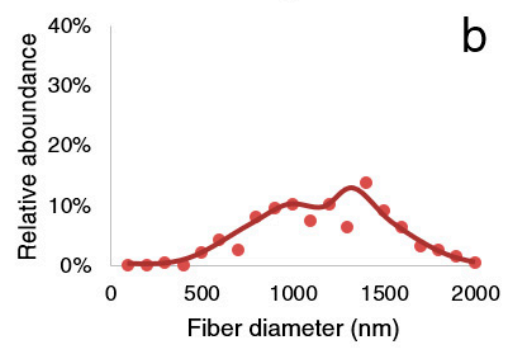

PLA+CyD

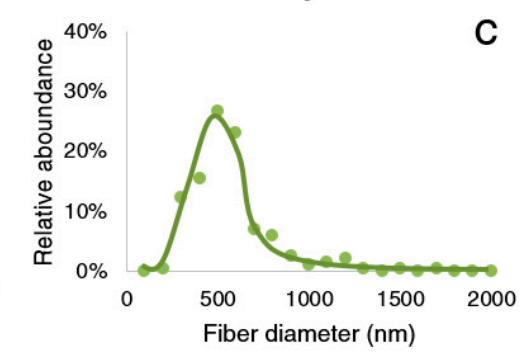

The fibrous filter pressure drops were measured at low face velocity. Pressure drop and outlet air velocity, as a function of the fiber type and fiber loading values, have been reported in Table 1. 
Table 1. Composition and characterization of the electrospun filter media.

\begin{tabular}{|c|c|c|c|c|c|c|}
\hline \multirow{2}{*}{ Filter } & \multicolumn{2}{|c|}{ Solution } & \multirow{2}{*}{ CyD } & \multirow{2}{*}{$\begin{array}{c}\mathbf{v}_{\text {outlet }} \\
(\mathrm{m} / \mathrm{s})\end{array}$} & \multirow{2}{*}{$\begin{array}{c}\Delta \mathrm{P} \\
(\mathrm{Pa})\end{array}$} & \multirow{2}{*}{ Filter Loading $\left(\mathrm{mg} / \mathrm{cm}^{2}\right)$} \\
\hline & PLA & CyD & & & & \\
\hline PLA & $100 \%$ & 0 & - & 0.25 & 24.4 & 1.43 \\
\hline PLA/CyD & $98.5 \%$ & $1.5 \%$ & - & 0.41 & 33.9 & 2.47 \\
\hline $\mathrm{PLA}+\mathrm{CyD}$ & $100 \%$ & - & $1.5 \%$ & 0.24 & 29.9 & 4.05 \\
\hline
\end{tabular}

Starting with these data, analyses on images were carried out to find out correlations with dimensions and morphology of the fibers. Observing the three filters (Figure 2), cyclodextrins influence the result of electrospinning and the overall measured pressure drop (Table 1, $\Delta \mathrm{P} 24.4,33.9$, and 29.9, respectively). PLA/CyD filters showed, apparently, more bulky fibers (Table 1, filter loading $\left(\mathrm{mg} / \mathrm{cm}^{2}\right.$ ), $1.43,2.47$, and 4.05) than the ones of PLA and PLA + CyD filters. This comparison justifies a higher drop pressure for this filter (33.9 Pa). Furthermore, crossing fibers enhance thickness determining a, probably, augmented capacity of sieving phenomena. PLA mix differentiates itself from PLA/CyD and PLA + CyD only for the addition of CyD.

\subsection{FTIR Spectroscopy}

FTIR spectroscopy was used to determine the interaction between both PLA and CyD and the composite and pollutants [24]. Obviously, due to not only the large number of functional groups present and the enormous variability of the compounds present in the polluting source used for the tests but also to the polymeric ones of the filter, it was not possible to identify with certainty the filtered molecules. It is instead possible to determine by the difference presence or absence of pollutants. In this regard, it was necessary to outline a spectroscopic profile of the materials used to make the filter itself, as well as study the interaction between the polymer and the CyDs. The enormous variety of compounds present in the polluting source does not always and unequivocally allow for the same peaks, so it is necessary to search for the traces of pollutant by evaluating the shifts and all the variations between the different peaks. Figure 4 reports a comparison between the untested and the tested PLA filter (without CyDs). The spectra of the pristine filter show the main peaks attributable to the PLA: At $2997-2944 \mathrm{~cm}^{-1}$ there are the symmetrical and the asymmetrical stretching of $\mathrm{CH}_{2}$ and $\mathrm{CH}_{3}$; the characteristic peak of a carbonyl group is at $1753 \mathrm{~cm}^{-1}$; at $1453 \mathrm{~cm}^{-1}$ there is the methyl in $\alpha$ position in respect to the carbonyl group; and in the region of $1380-1000 \mathrm{~cm}^{-1}$ the bending signals of $\mathrm{CH}_{2}$ and $\mathrm{CH}_{3}$.

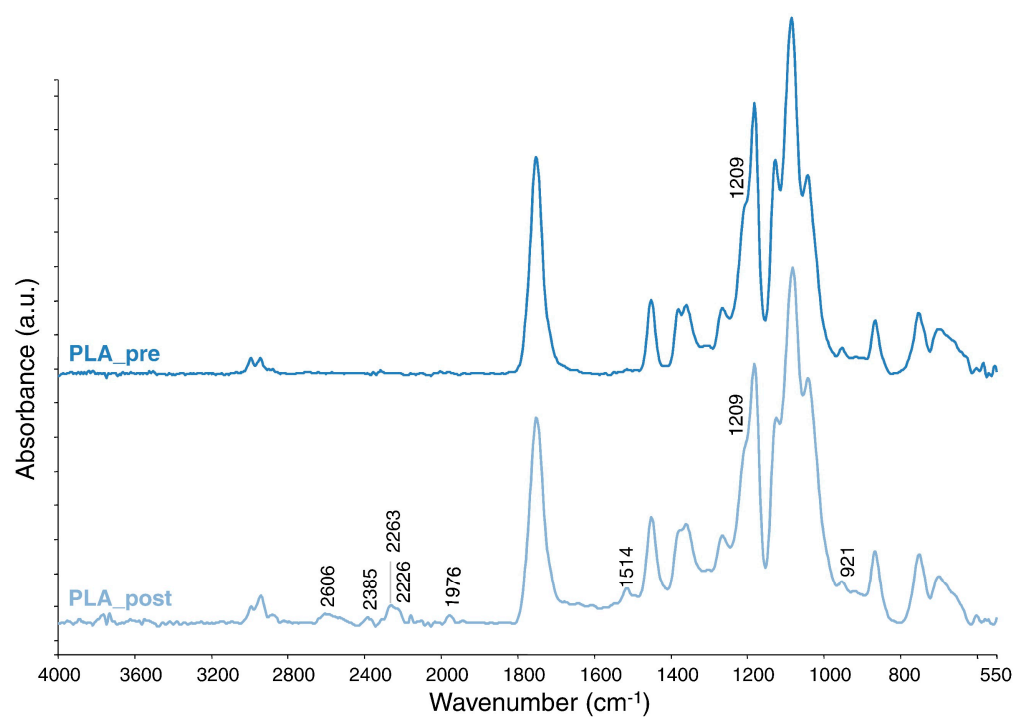

Figure 4. FTIR spectra of tested and untested PLA filters. 
In the other spectra, the different peaks caused by the interaction of the polymer with pollutants can be easily individuated: At 1644,1541,1514, $1301 \mathrm{~cm}^{-1}$, and $953 \mathrm{~cm}^{-1}$. Confronting the peak of the carbonyl group at $1753 \mathrm{~cm}^{-1}$ of the no tested filter with the same peak of the other samples reports a shift caused by the interaction between the polymer and the pollutant. It is possible to suppose the presence of nitro groups, reported by the peaks in the range of $1541 \mathrm{~cm}^{-1}$ and $1514 \mathrm{~cm}^{-1}$; the presence of aldehydes because of the shift at $1754 \mathrm{~cm}^{-1}$ and the peak at $1644 \mathrm{~cm}^{-1}$; and a carbon-nitrogen bound, due to the presence of a peak at $1301 \mathrm{~cm}^{-1}$.

The peak at $1514 \mathrm{~cm}^{-1}$ was very sharp with respect to the other spectrum, it is reasonable to assume that this was due to the concentration of pollutant adsorbed. A peak at $1514 \mathrm{~cm}^{-1}$ could be attributed or to a NO or a CN group. Moreover, it presents a series of peaks at 2601, 2385, 2263, and $1976 \mathrm{~cm}^{-1}$. Usually, in this range, there are signals from inorganic contaminants as, for example, thiocyanate. Considering the $\mathrm{CN}$ at $1514 \mathrm{~cm}^{-1}$ at the level of bands' ratio, the signal of the triple bonds is present at $2200 \mathrm{~cm}^{-1}$, the -SH group is at $2600 \mathrm{~cm}^{-1}$, and the signal of SCN is at $2100 \mathrm{~cm}^{-1}$. The peak at $1209 \mathrm{~cm}^{-1}$ is different in terms of height, therefore the concentration of the respective group increases after the filtration, so a pollutant containing the same group is attached to the filter. Lastly, at $921 \mathrm{~cm}^{-1}$ a new peak appears, which was absent in the pristine filter, so it may be relative to the deposited pollutant.

For what concerns the filters made with the addition of cyclodextrins (PLA/CyD and PLA + $\mathrm{CyD})$, it was important to determinate the possible interaction between the polymer and the CyD molecules, because during the electrospinning process these two compounds could interact causing the presence of new peaks independent from the wavelengths of the single compounds. It was necessary to determine the shifts and the new peaks on a no tested filter, not only to have a reference standard for the identification of the pollutant, but also to estimate the level of the bond between the two compounds. Figure 5 reports the spectra of the untested filter, made by adding CyD not only in the between of two layers of the polymer (PLA + CyD), but also in the polymer solution (PLA/CyD). Analyzing this spectrum, the absence of the characteristic peak of the hydroxylic group at $3400 \mathrm{~cm}^{-1}$ was immediately notable, because a large quantity of these groups were bonded with PLA in hydrogen bonds; but the peak at $1654 \mathrm{~cm}^{-1}$ indicates that there are still some free. All the values at 1000, 1021, 1077 , and $1151 \mathrm{~cm}^{-1}$ are shifted to 1040,1082,1124, and $1182 \mathrm{~cm}^{-1}$ because of the hydrogen bonds between the two compounds. Furthermore, the peak at $850 \mathrm{~cm}^{-1}$, typical of C-C bond, is shifted to $916 \mathrm{~cm}^{-1}$. The shift of the signal can be caused not only by the formation of new bonds but also by the sum of two different signals in the same region.

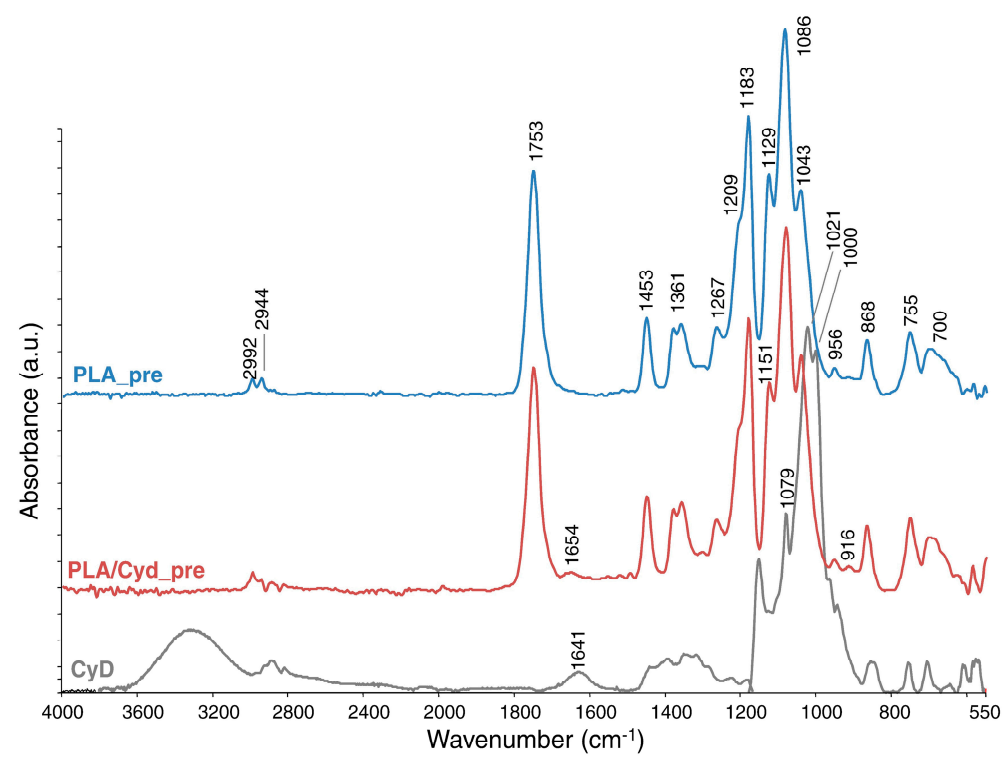

Figure 5. Typical spectra of the filter containing PLA and CyDs. 
After the reference spectra for the filters containing $\mathrm{CyD}$, also the tested spectra were examined (Figure 6).

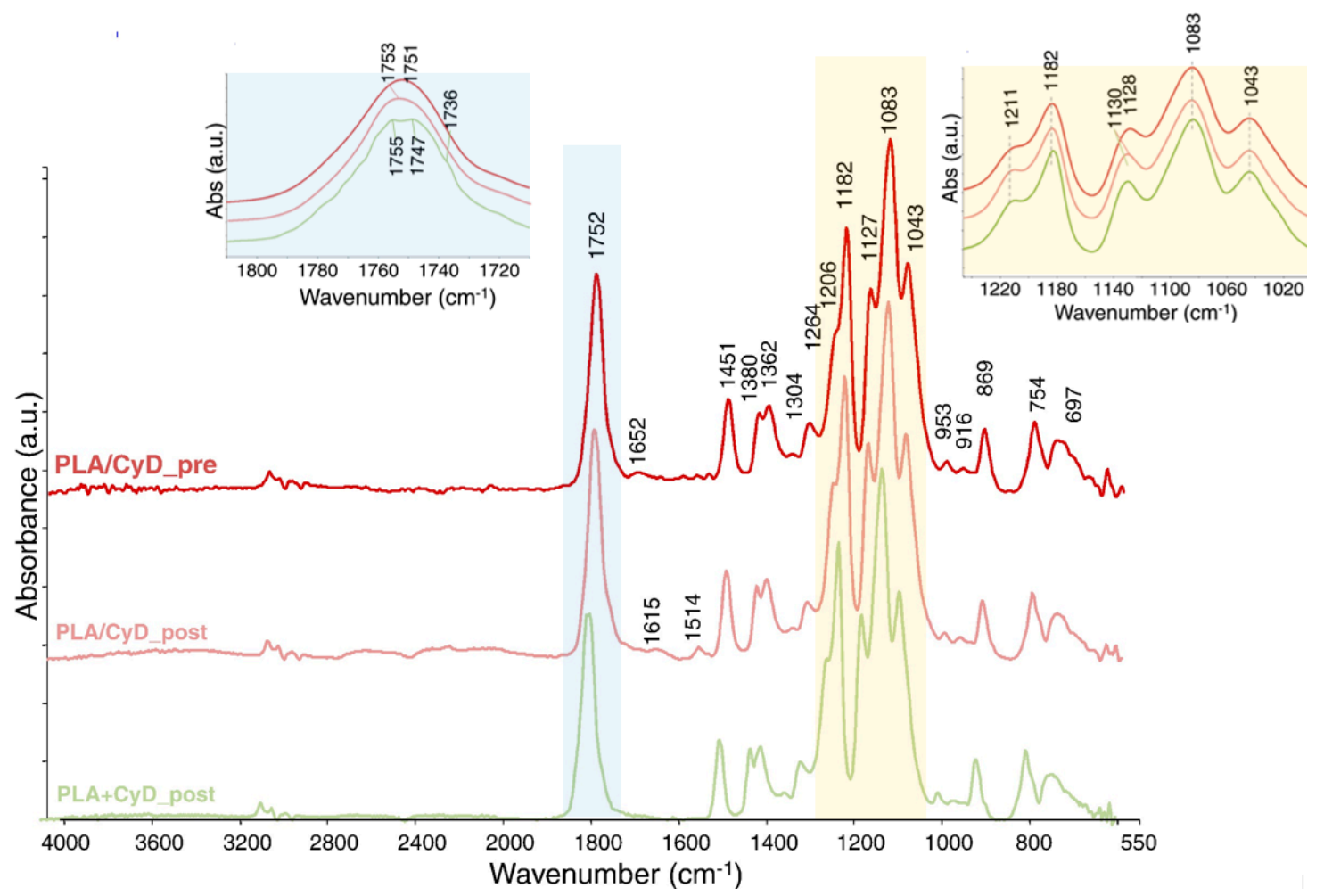

Figure 6. Comparison between all the filters containing cyclodextrins.

In these samples the presence of contaminates was represented by two main behaviors: The most important was the split of the carbonyl peak and its slightly shift; the other change was the shift of all the characteristic bands in the range from $1220 \mathrm{~cm}^{-1}$ to $1000 \mathrm{~cm}^{-1}$. The split of the carbonyl group can indicate the presence of another molecule with a similar configuration (for instance it can be an aldehyde or a ketone). Moreover, these kinds of pollutants may cause also the shoulder at $1736 \mathrm{~cm}^{-1}$. Other particular peaks are present at $3377 \mathrm{~cm}^{-1}$ for PLA/Cyd: The peak at $3377 \mathrm{~cm}^{-1}$ can be attributed to a compound with $\mathrm{NH}$ group, seeing as there are also peaks at 1615 and $1514 \mathrm{~cm}^{-1}$, which usually indicate the presence of $\mathrm{NH}_{2}$ and of a carbon bonded to nitrogen. The series of peaks in the range from 870 to $700 \mathrm{~cm}^{-1}$ are typical of $\mathrm{CH}$ groups: In these cases, they are different from the reference because of their shape and their shift, indicating the presence of another compound different from cyclodextrins or PLA.

\subsection{PM and VOC Removal Tests}

The $\mathrm{PM}_{1}, \mathrm{PM}_{2.5}$, and $\mathrm{PM}_{10}$ removal by different fibrous filters is shown in Figure 7a. From the PM efficiency removal comparison, it was possible to observe that the PLA + Cyd had the highest removal of both smaller particles, while all the different samples exhibited an efficiency higher than $97 \%$ for particles having diameter greater than $2.5 \mu \mathrm{m}$.

The characteristic conical configuration of cyclodextrins [12] is suitable for the formation of complexes of inclusion through non-covalent interactions: In fact, hydrophobic molecules are maintained in the cavity, blocking their passage through the filter. 

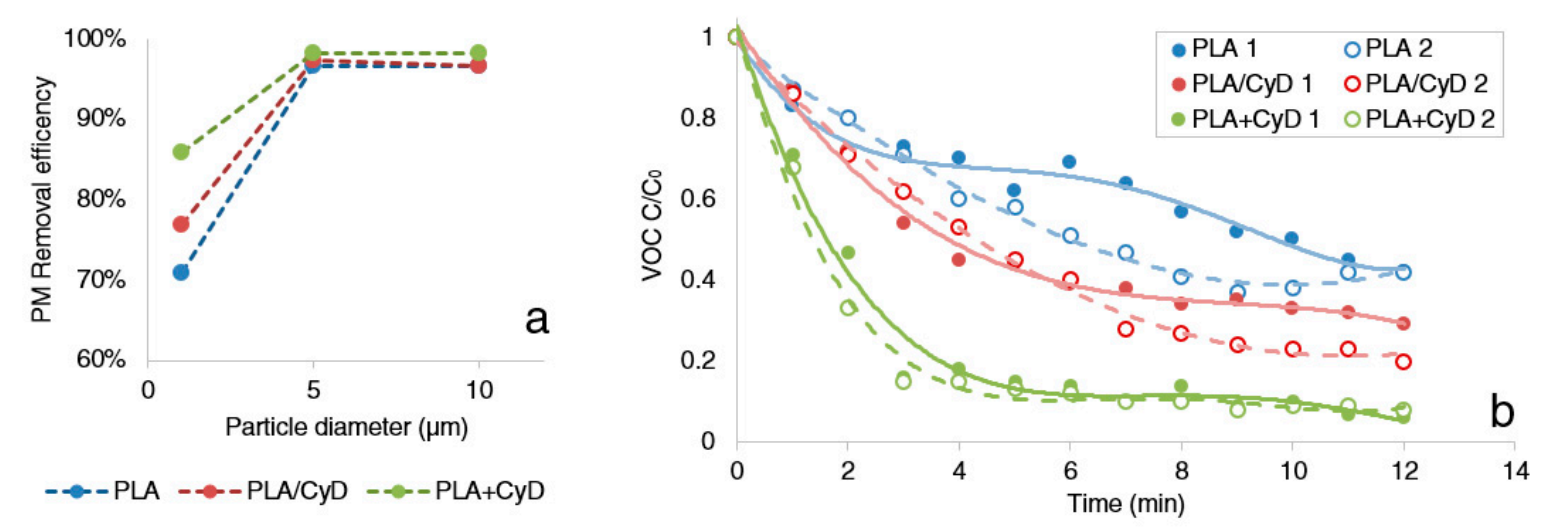

Figure 7. (a) PM removal efficiency and (b) normalized volatile organic compounds (VOC) concentration versus time by the different fibrous filters.

This mechanism of filtration should be added, according to classical filtration theory, to the other five mechanism effects to catch particles (interception, inertial, diffusion, gravity, and static electricity effect) [25] to catch also other smaller molecules as VOCs. In this way, CyD plays a role both in affecting the fiber morphology, resulting in thicker fibers and reduced cavities, and, actively, as surface centers for the capture of PM and VOCs, due to their dual hydrophilic/hydrophobic nature. The presence of $\mathrm{CyD}$ molecules at the surface of the fibers has a large influence on the molecular filtration capability [26]. The presence of more CyDs on the surface of the fibers implies a higher availability of sites for the bond with the pollutants, so it is reasonable to assume that higher concentration of $\mathrm{CyDs}$ are beneficial for the overall filtration efficiency. Nevertheless, the superficial availability of adsorption centers will affect, also, the blocking capacity of PMs and the resulting pressure drop. For all these reasons, the amount of CyDs must be enough to be bonded to the polymer and sufficient to have the possibility to create hydrogen bond with the pollutants.

During the electrospinning, CyD molecules could phase separate from PLA matrix and formed heterogeneous dispersion during solvent evaporation in the electrospinning process: This is likely because CyD has a hydrophilic characteristic and PLA is a hydrophobic polymer [26]. A heterogenic solution may cause a not homogeneous presence of CyDs on the fiber surface, causing a not homogenous filter.

VOCs removal is shown in Figure $7 \mathrm{~b}$. In this graph, it is possible to compare the three different tested filters in two subsequent situations. These tests were conducted injecting Toluene in the box. The first curve is about the behavior with $100 \mu \mathrm{L}$ of Toluene (in Figure $7 \mathrm{~b}$ labelled with 1 ). After about $30 \mathrm{~min}$ and as curves reach a plateau or their background concentration, the second injection of Toluene was carried out $(20 \mu \mathrm{L}$ ). This second injection (in Figure $7 \mathrm{~b}$ labelled with 2 ) is sufficient to obtain an initial concentration of Toluene comparable to the first one. The purpose of this method consists in investigating repeatability of tests and in the first evaluation of the durability of filters. As it was expected, filters with cyclodextrins allow quicker removal of VOCs, referred to PLA only fibers. Besides, it can be observed that the two normalized curves are almost overlapped, highlighting a factual constant behavior, for two subsequent tests at high concentration at least.

The presence of cyclodextrins in filters points out an increased capacity in the removal of VOCs. This condition suggests that VOCs removal tests highlight the contribution of the CyD on adsorption. Thus, the CyD can empower the removal of VOCs in two different ways. It is probable that in PLA/CyD filters VOCs are removed when CyD have their hole available. In PLA + CyD filters, VOCs are removed when they collide with $\mathrm{CyD}$ powder with an enhanced capacity of removal because of entire exposure to air, with a higher number of available sites.

A non-exhaustive comparison of the obtained results with the one reported in the literature is reported in Table 2. 
Table 2. Comparison of the obtained filtration results with the ones reported in the literature.

\begin{tabular}{|c|c|c|c|}
\hline Electrospun Polymer & Efficiency & Comments & Ref \\
\hline PLA & $99.997 \%(165.3 \mathrm{~Pa})$ & $\begin{array}{l}\text { Small fiber diameter and the presence of additional } \\
\text { mesopores on the beads were conducive to the capture } \\
\text { and adsorption of particulates. }\end{array}$ & [11] \\
\hline $\mathrm{PLA} / \mathrm{TiO}_{2}$ & $99.996 \%(128.7 \mathrm{~Pa})$ & $\begin{array}{c}\text { Relative humidity of } 45 \% \text { and face velocity of } 5.3 \mathrm{~cm} / \mathrm{s} \\
\text { and a high antibacterial activity of } 99.5 \%\end{array}$ & [27] \\
\hline PLA/CNPs & $\begin{array}{c}98.99 \% \\
(147.60 \mathrm{~Pa})\end{array}$ & $\begin{array}{c}\text { Air flow rate of } 14 \mathrm{~cm} / \mathrm{s} . \text { PLA/chitosan fibers show a } \\
\text { highly porous structure }\end{array}$ & [28] \\
\hline $\mathrm{PVA} / \mathrm{CNCs}$ & $\begin{array}{r}99.1 \% \\
(91 \mathrm{~Pa})\end{array}$ & Tests with PM2.5 and airflow velocity of $0.2 \mathrm{~m} / \mathrm{s}$ & [29] \\
\hline $\begin{array}{l}\text { Hierarchical structured } \\
\text { nano-sized/porous PLA }\end{array}$ & $\begin{array}{l}99.999 \% \\
(93.3 \mathrm{~Pa})\end{array}$ & $\begin{array}{l}\text { PLA-N/PLA-P double-layer structured membrane with } \\
\text { a mass ratio of } 1 / 5 \text {. Face velocity of } 5.3 \mathrm{~cm} / \mathrm{s}\end{array}$ & [30] \\
\hline PAN & $\begin{array}{l}>99 \% \\
(27 \mathrm{~Pa})\end{array}$ & $\begin{array}{c}\text { Nanobeads are useful for reducing the packing density } \\
\text { and the pressure drop through the filter. Ultrafine } \\
\text { nanofibers guarantee the PM removal efficiency. } \\
\text { Airflow rate of } 4.2 \mathrm{~cm} / \mathrm{s}\end{array}$ & [31] \\
\hline PLA/CyD & $>98 \%(30 \mathrm{~Pa})$ & & $\begin{array}{l}\text { This } \\
\text { study }\end{array}$ \\
\hline
\end{tabular}

DMAC: Dimethylacetamide; CNPs: Chitosan nanoparticles; and CNCs: Cellulose nanocrystals

\section{Conclusions}

The addition of $\mathrm{CyD}$, both in bulk and powder, determines an increase of removal efficiency of VOCs and PM1 size fraction, due to two different effects: The CyD in bulk affect the PLA fibers morphology, while the superficially deposited CyD directly affect the removal of the VOC. Efficiency tests highlight enhanced VOC removal efficiency in PLA/CyD and PLA + CyD filters; the FTIR analysis confirms that in filters containing CyDs the traces of the interaction between the pollutants and the filter were more evident, showing shifted and larger bands, and split and sharper peaks. Further studies will involve the investigation of the VOC type on the adsorption property, with the simultaneous addition of functional composites and the aim of synthesizing such composite from starch-food wastes. The use of CyDs from food wastes in air filtration systems will improve their positive environmental impact in a circular economy perspective for being used in air filtration applications.

Supplementary Materials: The following are available online at http://www.mdpi.com/2504-477X/4/2/79/s1, Figure S1: (a) 3D-printed PLA-support; (b) electrospinning of the PLA solution, (c) the electrospun filter. Figure S2: FTIR spectra of tested and untested PLA filters.

Author Contributions: Conceptualization, S.P., M.P., L.R. and S.Q.; Data curation, M.P., S.P., L.R.; Formal analysis, S.P., L.R. and M.L.R.; Investigation, S.P., L.R. and S.Q.; Methodology, S.P., M.P., L.R. and S.Q.; Project administration, M.L.R.; Resources, S.Q. and M.L.R.; Supervision, M.L.R.; Writing—original draft, S.P. and L.R.; Writing一review \& editing, M.P., and M.L.R. All authors have read and agreed to the published version of the manuscript.

Funding: This research received no external funding.

Acknowledgments: We would like to thank: Total Corbion PLA for providing the PLA and Simona Sabbatini from the SIMAU (Department of Materials, Enviromental Sciences and Urban Planning) for the FTIR measurements.

Conflicts of Interest: The authors declare no conflict of interest.

\section{References}

1. Reneker, D.H.; Yarin, A.L.; Zussman, E.; Xu, H. Electrospinning of nanofibers from polymer solutions. Polym. (Guildf). 2007. [CrossRef]

2. Krishnan, R.; Sundarrajan, S.; Ramakrishna, S. Green processing of nanofibers for regenerative medicine. Macromol. Mater. Eng. 2012, 298. [CrossRef]

3. Pierpaoli, M.; Ruello, M.L. IAQ: A bibliometric study. Sustainability 2018, 10, 3830. [CrossRef]

4. Yang, F.; Murugan, R.; Wang, S.; Ramakrishna, S. Electrospinning of nano/micro scale poly(l-lactic acid) aligned fibers and their potential in neural tissue engineering. Biomaterials 2005, 26, 2603-2610. [CrossRef] [PubMed] 
5. Mohammadian, M.; Haghi, A.K. Systematic parameter study for nano-fiber fabrication via electrospinning process. Bulg. Chem. Commun. 2014, 46, 545-555. [CrossRef]

6. Chakraborty, S.; Liao, I.C.; Adler, A.; Leong, K.W. Electrohydrodynamics: A facile technique to fabricate drug delivery systems. Adv. Drug Deliv. Rev. 2009, 61, 1043-1054. [CrossRef]

7. You, Y.; Won, S.; Jin, S.; Ho, W. Thermal interfiber bonding of electrospun poly ( L -lactic acid ) nanofibers. Mater. Lett. 2006, 60, 1331-1333. [CrossRef]

8. Park, J.; Lee, I. Controlled release of ketoprofen from electrospun porous polylactic acid ( PLA ) nanofibers. J. Polym. Res. 2011, 1287-1291. [CrossRef]

9. Li, Y.; Lim, C.T.; Kotaki, M. Study on structural and mechanical properties of porous PLA nanofibers electrospun by channel-based electrospinning system. Polym. (UK) 2015, 56, 572-580. [CrossRef]

10. Casasola, R.; Thomas, N.L.; Trybala, A.; Georgiadou, S. Electrospun poly lactic acid (PLA) fibres: Effect of different solvent systems on fibre morphology and diameter. Polym. (UK) 2014, 55, 4728-4737. [CrossRef]

11. Wang, Z.; Zhao, C.; Pan, Z. Porous bead-on-string poly(lactic acid) fibrous membranes for air filtration. J. Colloid Interface Sci. 2015, 441, 121-129. [CrossRef]

12. Aulton, M.E.; Taylor, K.M.G. Tecnologie Farmaceutiche-Progettazione e Allestimento dei Medicinali; Edra: London, UK, 2015.

13. Sliwa, W.; Girek, T. Cyclodextrins. Properties and Application; Wiley-VCH: Hoboken, NJ, USA, 2017.

14. Kayaci, F.; Umu, O.C.O.; Tekinay, T.; Uyar, T. Antibacterial electrospun poly(lactic acid) (pla) nanofibrous webs incorporating Triclosan/Cyclodextrin inclusion complexes. J. Agric. Food Chem. 2013. [CrossRef]

15. Arkas, M.; Allabashi, R.; Tsiourvas, D.; Mattausch, E.M.; Perfler, R. Organic/inorganic hybrid filters based on dendritic and cyclodextrin "nanosponges" for the removal of organic pollutants from water. Env. Sci. Technol. 2006, 40, 2771-2777. [CrossRef] [PubMed]

16. Favier, I.M.; Baudelet, D.; Fourmentin, S. VOC Trapping by New Crosslinked Cyclodextrin Polymers. In Proceedings of the Journal of Inclusion Phenomena and Macrocyclic Chemistry; Springer: New York, NY, USA, 2011; Volume 69, pp. 433-437.

17. Wen, P.; Zhu, D.H.; Feng, K.; Liu, F.J.; Lou, W.Y.; Li, N.; Zong, M.H.; Wu, H. Fabrication of electrospun polylactic acid nanofilm incorporating cinnamon essential oil/ $\beta$-cyclodextrin inclusion complex for antimicrobial packaging. Food Chem. 2016, 196, 996-1004. [CrossRef] [PubMed]

18. Aytac, Z.; Kusku, S.I.; Durgun, E.; Uyar, T. Encapsulation of gallic acid/cyclodextrin inclusion complex in electrospun polylactic acid nanofibers: Release behavior and antioxidant activity of gallic acid. Mater. Sci. Eng. C 2016, 63, 231-239. [CrossRef] [PubMed]

19. Loftsson, T.; Duchêne, D. Cyclodextrins and their pharmaceutical applications. Int. J. Pharm. 2007, 329, 1-11. [CrossRef]

20. Butterfield, M.T.; Agbaria, R.A.; Warner, I.M. Extraction of volatile PAHs from air by use of solid cyclodextrin. Anal. Chem. 1996, 68, 1187-1190. [CrossRef]

21. Crini, G.; Peindy, H.N.; Gimbert, F.; Robert, C. Removal of C.I. Basic Green 4 (Malachite Green) from aqueous solutions by adsorption using cyclodextrin-based adsorbent: Kinetic and equilibrium studies. Sep. Purif. Technol. 2007, 53, 97-110. [CrossRef]

22. Alsbaiee, A.; Smith, B.J.; Xiao, L.; Ling, Y.; Helbling, D.E.; Dichtel, W.R. Rapid removal of organic micropollutants from water by a porous $\beta$-cyclodextrin polymer. Nature 2016, 529, 190-194. [CrossRef]

23. Pierpaoli, M.; Riderelli, L.; Palmieri, S.; Fava, G.; Ruello, M.L. Transparent Electrospun PLA-nanofibers on 3D-printed Honeycomb for a High-efficient Air Filtration. In Proceedings of the Indoor Air 2018, Philadelphia, PA, USA, 22-27 July 2018.

24. Medhurst, L.J. FTIR determination of pollutants in automobile exhaust: An environmental chemistry experiment comparing cold-start and warm-engine conditions. J. Chem. Educ. 2005, 82, 278. [CrossRef]

25. Qin, X.; Wang, S. Filtration properties of electrospinning nanofibers. Mater. Sci. 2006, 102, 1285-1290. [CrossRef]

26. Uyar, T.; Havelund, R.; Hacaloglu, J.; Besenbacher, Ḱ.F.; Kingshott, P. Cyclodextrins: Comparison of molecular filter performance. Acs Nano 2010, 4, 5121-5130. [CrossRef] [PubMed]

27. Wang, Z.; Pan, Z.; Wang, J.; Zhao, R. A Novel Hierarchical Structured Poly(lactic acid)/Titania Fibrous Membrane with Excellent Antibacterial Activity and Air Filtration Performance. J. Nanomater. 2016, $2016,17$. [CrossRef] 
28. Li, H.; Wang, Z.; Zhang, H.; Pan, Z. Nanoporous PLA/(Chitosan Nanoparticle) composite fibrous membranes with excellent air filtration and antibacterial performance. Polym. (Basel) 2018, 10, 1085. [CrossRef] [PubMed]

29. Zhang, Q.; Li, Q.; Young, T.M.; Harper, D.P.; Wang, S. A novel method for fabricating an electrospun poly(vinyl alcohol)/cellulose nanocrystals composite nanofibrous filter with low air resistance for high-efficiency filtration of particulate matter. Acs Sustain. Chem. Eng. 2019, 7, 8706-8714. [CrossRef]

30. Wang, Z.; Pan, Z. Preparation of hierarchical structured nano-sized/porous poly(lactic acid) composite fibrous membranes for air filtration. Appl. Surf. Sci. 2015. [CrossRef]

31. Huang, J.J.; Tian, Y.; Wang, R.; Tian, M.; Liao, Y. Fabrication of bead-on-string polyacrylonitrile nanofibrous air filters with superior filtration efficiency and ultralow pressure drop. Sep. Purif. Technol. 2020, 237, 116377. [CrossRef]

(C) 2020 by the authors. Licensee MDPI, Basel, Switzerland. This article is an open access article distributed under the terms and conditions of the Creative Commons Attribution (CC BY) license (http://creativecommons.org/licenses/by/4.0/). 